\title{
Public Health Impact of Achieving 80\% Colorectal Cancer Screening Rates in the United States by 2018
}

\author{
Reinier G. S. Meester, MS; Chyke A. Doubeni, MD, MPH ${ }^{2,3}$; Ann G. Zauber, PhD; S. Luuk Goede, MPH'; \\ Theodore R. Levin, MD 5 ; Douglas A. Corley, MD, PhD ${ }^{5}$; Ahmedin Jemal, DVM, PhD ${ }^{6}$; and Iris Lansdorp-Vogelaar, PhD ${ }^{1}$
}

BACKGROUND: The National Colorectal Cancer Roundtable, a national coalition of public, private, and voluntary organizations, has recently announced an initiative to increase colorectal cancer (CRC) screening rates in the United States to $80 \%$ by 2018 . The authors evaluated the potential public health benefits of achieving this goal. METHODS: The authors simulated the 1980 through 2030 United States population of individuals aged 50 to 100 years using microsimulation modeling. Test-specific historical screening rates were based on National Health Interview Survey data for 1987 through 2013. The effects of increasing screening rates from approximately $58 \%$ in 2013 to $80 \%$ in 2018 were compared to a scenario in which the screening rate remained approximately constant. The outcomes were cancer incidence and mortality rates and numbers of CRC cases and deaths during short-term follow-up (2013-2020) and extended follow-up (2013-2030). RESULTS: Increasing CRC screening rates to $80 \%$ by 2018 would reduce CRC incidence rates by $17 \%$ and mortality rates by $19 \%$ during short-term follow-up and by $22 \%$ and $33 \%$, respectively, during extended follow-up. These reductions would amount to a total of 277,000 averted new cancers and 203,000 averted CRC deaths from 2013 through 2030. CONCLUSIONS: Achieving the goal of increasing the uptake of CRC screening in the United States to $80 \%$ by 2018 may have a considerable public health impact by averting approximately 280,000 new cancer cases and 200,000 cancer deaths within $<20$ years. Cancer 2015;121:2281-5. ( 2015 The Authors. Cancer published by Wiley Periodicals, Inc. on behalf of American Cancer Society. This is an open access article under the terms of the Creative Commons Attribution-NonCommercial-NoDerivs License, which permits use and distribution in any medium, provided the original work is properly cited, the use is non-commercial and no modifications or adaptations are made.

KEYWORDS: public health, cancer screening, colorectal neoplasms, incidence, mortality.

\section{INTRODUCTION}

Colorectal cancer (CRC) is the fourth most commonly diagnosed cancer and the second leading cause of cancer death in the United States for both sexes combined, with 136,800 new cancer cases and 50,300 deaths estimated in $2014 .{ }^{1}$ Registry data from the past decade indicate that both disease incidence and mortality decreased by approximately $3 \%$ per year, ${ }^{2}$ largely due to the increased use of screening. ${ }^{3,4}$ Despite the effectiveness of screening and the availability of various screening options, only $58 \%$ of US adults aged 50 to 75 years had received guideline-recommended testing in 2013..$^{5}$ Previous studies have demonstrated that a substantial percentage of CRC deaths are attributable to nonuse of screening. ${ }^{6,7}$ This rallied a recent initiative from the National Colorectal Cancer Roundtable (NCCR), a national coalition of public, private, and voluntary organizations, to aim for screening rates of $80 \%$ in the United States by $2018 .{ }^{8}$ However, an estimate of the potential benefits of increasing uptake by an additional $22 \%$ in terms of the number of CRC cases and deaths averted is needed to inform public discourse and policy on this initiative and to project both the short-term and long-term public health "return on investment." In the current study, we used advanced modeling approaches to estimate the potential benefits in terms of new CRC cases and deaths averted from achieving the NCCR goal.

\section{MATERIALS AND METHODS}

The current study was based on men and women aged 50 to 100 years, and was simulated to match the 1980 through 2030 US population in terms of their life expectancy, risk of CRC, and past and future use of screening. The analyses used

\footnotetext{
Corresponding author: Reinier G. S. Meester, MS, Department of Public Health, Erasmus MC University Medical Center, PO Box 2040 , 3000 CA Rotterdam, the Netherlands; Fax: (011) 31-10-703 84 75; r.meester@erasmusmc.nl.

${ }^{1}$ Department of Public Health, Erasmus MC University Medical Center, Rotterdam, the Netherlands; ${ }^{2}$ Department of Family Medicine and Community Health, and the Department of Epidemiology, Perelman School of Medicine, University of Pennsylvania, Philadelphia, Pennsylvania; ${ }^{3}$ Leonard Davis Center for Health Economics and Public Health Initiatives, University of Pennsylvania, Philadelphia, Pennsylvania; ${ }^{4}$ Department of Epidemiology and Biostatistics, Memorial Sloan Kettering Cancer Center, New York, New York; ${ }^{5}$ Division of Research, Kaiser Permanente, Oakland, California; ${ }^{6}$ Surveillance and Health Services Research, American Cancer Society, Atlanta, Georgia
}

See editorial on pages $2127-8$, this issue.

DOI: 10.1002/cncr.29336, Received: January 20, 2015; Accepted: February 9, 2015, Published online March 12, 2015 in Wiley Online Library (wileyonlinelibrary.com) 
the Microsimulation Screening Analysis-Colon (MISCAN-COLON) model, which has been used to inform US Preventive Services Task Force screening recommendations. ${ }^{\text {? }}$

\section{Microsimulation Model}

The MISCAN-COLON model is part of the Cancer Intervention and Surveillance Modeling Network (CISNET),${ }^{10}$ and has been described extensively elsewhere. ${ }^{11}$ The model integrates the natural history of CRC, its heterogeneity, outcomes, and the effects of screening and treatment. The model allows for the flexible evaluation of various screening scenarios by leveraging observed data. The modeled effects of screening demonstrate good concordance with several randomized screening trials. ${ }^{12-16}$

\section{Source Data}

Demography estimates were obtained from the US Census Bureau. ${ }^{17}$ Overall life expectancy was based on generational US life tables from the Berkeley Mortality Database. ${ }^{18}$ Age-specific and size-specific prevalence of adenomas was based on autopsy and colonoscopy data from before the era of screening. ${ }^{10}$ Age-, stage-, and location-specific cancer incidence was based on prescreening data (years 1975-1979) from the Surveillance, Epidemiology, and End Results program ${ }^{19}$; cancer survival was based on more recent Surveillance, Epidemiology, and End Results data (years 2000-2010).

Data regarding the historical use of colonoscopy, fecal occult blood tests, and sigmoidoscopy in the United States were derived from data from the 1987 through 2013 National Health Interview Survey (NHIS). ${ }^{5}$ In $2013,58 \%$ of the population aged 50 to 75 years reported being up-to-date on screening. The percentages that were up-to-date with each specific test were $54 \%$ for colonoscopy, $8 \%$ for fecal occult blood tests, and $4 \%$ for sigmoidoscopy.

\section{Screening Scenarios}

In the current analysis, we evaluated a scenario in which the screening rate increased linearly from $58 \%$ in 2013 to $80 \%$ in 2018 , with no further increase occurring through 2030. We compared this scenario to one in which screening rates remained constant at approximately $60 \%$. We evaluated the magnitude of the reduction in CRC incidence and mortality rates per year during both short-term (2013-2020) and extended (2013-2030) follow-up. Screening consisted of a mix of colonoscopy, sigmoidoscopy, and fecal occult blood testing in accordance with estimates from the NHIS. Patients with a positive fecal
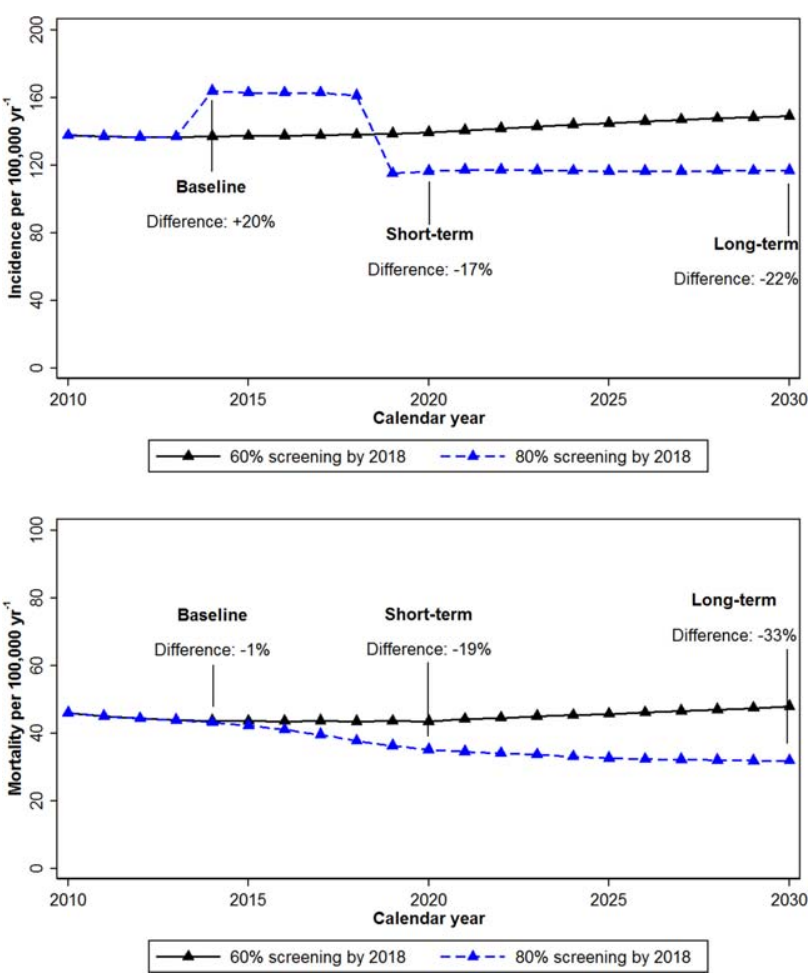

Figure 1. Crude colorectal cancer (Top) incidence and (Bottom) mortality rates in the US population aged $\geq 50$ years, under 2 scenarios of screening uptake. In the first scenario, reported screening rates remained at a constant level of approximately 60\% from 2013 through 2030, whereas in the other scenario, screening rates increased from $60 \%$ to $80 \%$ by 2018 and remained constant thereafter.

occult blood test or sigmoidoscopy (for adenomas or cancer) were referred to diagnostic colonoscopy and patients in whom adenomas were detected were referred for colonoscopic surveillance according to guidelines from the US Multi-Society Task Force on Colorectal Cancer. ${ }^{20}$ Patient adherence to diagnostic colonoscopy and surveillance colonoscopy was assumed to be $80 \%{ }^{21,22}$

\section{RESULTS}

\section{Incidence Rates and Avoidable New Cancer Cases}

Under the assumption of approximately constant CRC screening levels in the United States between 2013 and 2030 , the crude CRC incidence rate per 100,000 population per year would increase from 137 in the first year of follow-up (2014) to 149 in 2030 (Fig. 1 Top) due to aging of the population. If screening uptake increased from $58 \%$ in 2013 to $80 \%$ in 2018 , the incidence rates (per 100,000 population) would decrease from 164 in 2014 to 117 in 2030. Compared with a scenario of constant CRC screening levels, the goal of " $80 \%$ by 2018 " would initially increase CRC incidence rates by $20 \%$ in 2014 
because of the early detection of CRC among previously unscreened individuals, but subsequently decrease the incidence rates by $17 \%$ by 2020 and by $22 \%$ by 2030 . With the estimated population of individuals aged 50 to 100 years expected to increase from 108 million in 2014 to 133 million by 2030 , the above effects on incidence and mortality rates would result in 43,000 averted cases per year by 2030 , and a total of 277,000 cases averted from 2013 through 2030 (Table 1).

\section{Mortality Rates and Avoidable Cancer Deaths}

There would be an immediate mortality benefit of increasing CRC screening rates to $80 \%$ by 2018 . While the crude CRC mortality rate per 100,000 population would increase from 44 in 2014 to 48 in 2030 under constant screening levels of $60 \%$, the mortality rate would decrease from 43 to 32 with an $80 \%$ CRC screening rate by 2018 . Thus, the relative effect of the " $80 \%$ by 2018 " goal would be a $1 \%$ decrease in the CRC mortality rate by 2014 , a decrease of $19 \%$ in 2020 , and a decrease of $33 \%$ in 2030 (Fig. 1 Bottom). This would translate to 21,000 averted cancer deaths per year by 2030 , and a total of 203,000 averted deaths from 2013 through 2030 (Table 1).

\section{DISCUSSION}

We used microsimulation modeling to estimate the potential US public health impact of achieving the NCCR goal to increase CRC screening rates from $<60 \%$ in 2013 to $80 \%$ by 2018 . The results of the current study suggest that achieving this goal may produce a reduction of $22 \%$ in CRC incidence rates and 33\% in CRC mortality rates by 2030 , which translates to approximately 280,000 averted new cases and 200,000 averted deaths from 2013 through 2030.

The 20\% increase in CRC screening uptake from $60 \%$ to $80 \%$ has a projected high impact on CRC mortality (reduction of $33 \%$ ). This $33 \%$ matches well with our recent estimate that the majority of current CRC mortality $(60 \%)$ is attributable to nonuse of screening. ${ }^{7}$ The increase in screening uptake from $60 \%$ to $80 \%$ decreases the number of underscreened individuals by approximately $50 \%$ and consequently reduces overall CRC mortality by roughly one-half the "population attributable fraction.”

Within the underscreened population, the impact of the goal of " $80 \%$ by 2018 " will be larger than the overall reductions in incidence and mortality of $20 \%$ to $30 \%$ for the population because the majority of avoidable cases and deaths occur within the $40 \%$ of the population that is
TABLE 1. Difference in the Number of CRC Cases and Deaths Per Year When Achieving CRC Screening Rates of $80 \%$ in the United States by 2018 , Compared With Constant Screening Rates of $60 \%$

\begin{tabular}{lrrrrr}
\hline \multicolumn{5}{c}{ Calendar Year } \\
\cline { 2 - 6 } & 2014 & 2018 & 2022 & 2026 & 2030 \\
\hline \multicolumn{7}{c}{} & & & & \\
\hline Difference in no. of CRC cases & (thousands) & & \\
Per year & 29 & 27 & -30 & -38 & -43 \\
Cumulative & 29 & 141 & 28 & -112 & -277 \\
Difference in no. of CRC deaths (thousands) & & & \\
Per year & -1 & -7 & -13 & -18 & -21 \\
Cumulative & -1 & -17 & -60 & -123 & -203 \\
\hline
\end{tabular}

Abbreviation: CRC, colorectal cancer.

underscreened. Underscreened individuals tend to have lower educational levels and income and to lack health insurance. $^{23}$ Thus, a desirable effect of achieving a CRC screening rate of $80 \%$ by 2018 is the potential to reduce CRC health disparities in the United States, which is an important Healthy People 2020 objective. ${ }^{24}$

To our knowledge, no prior study has estimated the public health benefits of the goal of " $80 \%$ by 2018 ." Several studies have estimated the potential contribution of screening to decreases in CRC incidence and mortality in the United States. ${ }^{3,4,25,26}$ The current study estimates of screening benefits appear to be somewhat smaller than noted by Ladabaum and Song ${ }^{25}$ and larger than those from Edwards et $\mathrm{al}^{3}$ and Yang et al. ${ }^{4}$ This is likely due to different study designs or periods, and differences in assumptions regarding the effectiveness of colonoscopy screening. For colonoscopy, the effectiveness of screening is less well established than for other recommended screening tests due to the absence of evidence from randomized controlled trials. The effectiveness of endoscopy screening in the MISCAN-COLON model was recently increased based on the outcomes of the UK flexible sigmoidoscopy study. ${ }^{27}$ This change explains the slightly higher impact of increasing screening uptake in this study compared with earlier studies. ${ }^{3,26}$ We evaluated a more conservative assumption for colonoscopy efficacy in which colonoscopy sensitivity for small adenomas was decreased by $50 \%$; this decreased the impact of a CRC screening rate of $80 \%$ by 2018 on CRC incidence, but did not appear to substantively influence the mortality benefits (data not shown).

There are some limitations to the current study. First, we evaluated only 1 of 2 possible ways to increase screening rates in the United States, namely by expanding screening to previously unscreened individuals. An alternative way is to reduce the number of individuals who 
have been screened but not according to screening recommendations. In the latest NHIS data from 2013, the percentage of the population that ever underwent CRC screening, but not within the recommended intervals, was $7.4 \%{ }^{5}$ Thus, in a strategy of encouraging both higher guideline adherence in previously screened individuals and the participation of previously unscreened individuals, the former approach could contribute approximately one-third $(7.4 \%)$ to the overall targeted increase of $22 \%$ in screening rates. This may lead to a somewhat lower public health impact for the " $80 \%$ by 2018 " goal than we found because the impact of screening is lower in previously screened individuals compared with unscreened individuals.

Second, we assumed that the percentage of endoscopy versus fecal-based examinations and its quality remained the same in the population when screening uptake was increased, whereas higher uptake of fecal immunochemical testing or other stool-based tests may be needed to achieve the ideal of an $80 \%$ screening rate. ${ }^{28,29}$ A higher percentage of stool-based tests than was modeled may affect the projected benefits of increased screening uptake, although modeling analyses have demonstrated that the potential benefit of 10-year colonoscopy and annual fecal immunochemical testing may be comparable. Colonoscopy quality is known to vary widely among providers and is highly correlated with disease outcomes. ${ }^{30}$ If expanding screening, in part, was achieved through examiners with lower detection rates, then the benefits may be less than projected.

Finally, there may be CRC disparities between screened and underscreened populations beyond those attributable to screening. ${ }^{31}$ If the background CRC risk in the underscreened population is higher and/or CRC survival is poorer, the impact of reaching an $80 \%$ screening rate by 2018 may be even larger.

The outcomes of the current study were confined to CRC incidence and mortality in the population, and did not include years of life lost to CRC, costs, and potential harms of screening. Previous analyses have indicated that CRC screening is likely highly cost-effective, ${ }^{11,32}$ and may even be cost-saving, ${ }^{33}$ making increasing screening not only desirable from a perspective of cancer control but also from a financial perspective. However, these analyses usually do not consider potential overuse of screening and surveillance, ${ }^{34}$ program costs, ${ }^{35}$ and especially resources needed to bring in the individuals to reach a goal of $80 \%$ uptake of screening.

There are many barriers to increasing CRC screening uptake in the United States, only some of which are the target of health care reforms under the Patient Protection and Affordable Care Act. ${ }^{36,37}$ Substantial coordinated effort is needed to achieve the goal of an $80 \%$ CRC screening rate by 2018 in the United States. The results of the current study indicate that such investments may be well rewarded with long-term reductions in CRC incidence and mortality rates of $22 \%$ and $33 \%$, respectively, and the avoidance of 280,000 new CRC cases and 200,000 CRC deaths in $<20$ years.

\section{FUNDING SUPPORT}

Supported in part by grants from the National Cancer Institute (NCI) at the National Institutes of Health (U54 CA163262, U01 CA152959, U01 CA151736, and U24 CA171524) and the Intramural Research Department at the American Cancer Society (to Dr. Jemal). This study was conducted within the NCI-funded Population-Based Research Optimizing Screening through Personalized Regimens (PROSPR) consortium (NCI grant U54 CA163262), which aims to conduct multisite, coordinated, transdisciplinary research to evaluate and improve cancer screening. The modeling for the current study was partially supported by NCI grant U01 CA152959 (CISNET).

\section{CONFLICT OF INTEREST DISCLOSURES}

Dr. Doubeni has acted as a paid consultant for Exact Sciences for work performed outside of the current study.

\section{REFERENCES}

1. National Cancer Institute. SEER Cancer Statistics Factsheets: Colon and Rectum Cancer. Available at: http://seer.cancer.gov/statfacts/ html/colorect.html/. Accessed September Day, 2014.

2. Siegel R, Desantis C, Jemal A. Colorectal cancer statistics, 2014. CA Cancer J Clin. 2014;64:104-117.

3. Edwards BK, Ward E, Kohler BA, et al. Annual report to the nation on the status of cancer, 1975-2006, featuring colorectal cancer trends and impact of interventions (risk factors, screening, and treatment) to reduce future rates. Cancer. 2010;116:544-573.

4. Yang DX, Gross CP, Soulos PR, Yu JB. Estimating the magnitude of colorectal cancers prevented during the era of screening: 1976 to 2009. Cancer. 2014;120:2893-2901.

5. Centers for Disease Control and Prevention. National Health Interview Survey. Available at: http://www.cdc.gov/nchs/nhis.htm. Accessed March 1, 2014.

6. Stock C, Knudsen AB, Lansdorp-Vogelaar I, Haug U, Brenner H. Colorectal cancer mortality prevented by use and attributable to nonuse of colonoscopy. Gastrointest Endosc. 2011;73:435-443.e5.

7. Meester RG, Doubeni CA, Lansdorp-Vogelaar I, et al. Colorectal cancer deaths attributable to nonuse of screening in the United States. Ann Epidemiol. 2015;25:208-213.

8. American Cancer Society. The National Colorectal Cancer Roundtable. Available at: http://www.cancer.org/healthy/informationforhealthcareprofessionals/colonmdclinicansinformationsource/nationalcolorectalcancerroundtable/national-colorectal-cancer-roundtable. Accessed January 1, 2015.

9. Zauber AG, Lansdorp-Vogelaar I, Knudsen AB, Wilschut J, van Ballegooijen M, Kuntz KM. Evaluating test strategies for colorectal cancer screening: a decision analysis for the U.S. Preventive Services Task Force. Ann Intern Med. 2008;149:659-669.

10. Cancer Intervention and Surveillance Modeling Network (CISNET). Colorectal Cancer Model Profiles. Available at: http://cisnet.cancer. gov/colorectal/profiles.html/. Accessed January 1, 2013. 
11. van Hees F, Habbema JD, Meester RG, Lansdorp-Vogelaar I, van Ballegooijen M, Zauber AG. Should colorectal cancer screening be considered in elderly persons without previous screening? A costeffectiveness analysis. Ann Intern Med. 2014;160:750-759.

12. Winawer SJ, Zauber AG, Ho MN, et al. Prevention of colorectal cancer by colonoscopic polypectomy. The National Polyp Study Workgroup. N Engl J Med. 1993;329:1977-1981.

13. Winawer SJ, Zauber AG, O'Brien MJ, et al. Randomized comparison of surveillance intervals after colonoscopic removal of newly diagnosed adenomatous polyps. The National Polyp Study Workgroup. $N$ Engl J Med. 1993;328:901-906.

14. Hardcastle JD, Chamberlain JO, Robinson $\mathrm{MH}$, et al. Randomised controlled trial of faecal-occult-blood screening for colorectal cancer. Lancet. 1996;348:1472-1477.

15. Mandel JS, Church TR, Ederer F, Bond JH. Colorectal cancer mortality: effectiveness of biennial screening for fecal occult blood. J Natl Cancer Inst. 1999;91:434-437.

16. Jorgensen OD, Kronborg O, Fenger C. A randomised study of screening for colorectal cancer using faecal occult blood testing: results after 13 years and seven biennial screening rounds. Gut. 2002;50:29-32.

17. US Census Bureau. National Population Projections, 2000. Available at: http://www.census.gov/population/projections/. Accessed January day, 2015.

18. Berkeley Mortality Database. Lifetables by Year of Birth 1900-2000. Available at: http://www.demog.berkeley.edu/ -bmd/states.html. Accessed January 1, 2015.

19. Surveillance Research Program, National Cancer Institute. SEER*Stat Software, version 5.3.1. Available at: http://seer.cancer.gov/seerstat/. Accessed January 1, 2015.

20. Lieberman DA, Rex DK, Winawer SJ, et al; United States MultiSociety Task Force on Colorectal Cancer. Guidelines for colonoscopy surveillance after screening and polypectomy: a consensus update by the US Multi-Society Task Force on Colorectal Cancer. Gastroenterology. 2012;143:844-857.

21. van Rossum LG, van Rijn AF, Laheij RJ, et al. Random comparison of guaiac and immunochemical fecal occult blood tests for colorectal cancer in a screening population. Gastroenterology. 2008;135:82-90.

22. Colquhoun P, Chen HC, Kim JI, et al. High compliance rates observed for follow up colonoscopy post polypectomy are achievable outside of clinical trials: efficacy of polypectomy is not reduced by low compliance for follow up. Colorectal Dis. 2004;6:158-161.

23. Shapiro JA, Klabunde CN, Thompson TD, Nadel MR, Seeff LC, White A. Patterns of colorectal cancer test use, including CT colonography, in the 2010 National Health Interview Survey. Cancer Epidemiol Biomarkers Prev. 2012;21:895-904.

24. Healthy People 2020. Disparities. Available at: http://www.healthypeople.gov/2020/about/foundation-health-measures/Disparities. Accessed January 1, 2015.
25. Ladabaum U, Song K. Projected national impact of colorectal cancer screening on clinical and economic outcomes and health services demand. Gastroenterology. 2005;129:1151-1162.

26. Vogelaar I, van Ballegooijen M, Schrag D, et al. How much can current interventions reduce colorectal cancer mortality in the U.S.? Mortality projections for scenarios of risk-factor modification, screening, and treatment. Cancer. 2006;107:1624-1633.

27. Atkin WS, Edwards R, Kralj-Hans I, et al; UK Flexible Sigmoidoscopy Trial Investigators. Once-only flexible sigmoidoscopy screening in prevention of colorectal cancer: a multicentre randomised controlled trial. Lancet. 2010;375:1624-1633.

28. Inadomi JM, Vijan S, Janz NK, et al. Adherence to colorectal cancer screening: a randomized clinical trial of competing strategies. Arch Intern Med. 2012;172:575-582.

29. Gupta S, Halm EA, Rockey DC, et al. Comparative effectiveness of fecal immunochemical test outreach, colonoscopy outreach, and usual care for boosting colorectal cancer screening among the underserved: a randomized clinical trial. JAMA Intern Med. 2013;173: 1725-1732.

30. Corley DA, Jensen CD, Marks AR, et al. Adenoma detection rate and risk of colorectal cancer and death. $N$ Engl J Med. 2014;370: 1298-1306.

31. Lansdorp-Vogelaar I, Kuntz KM, Knudsen AB, van Ballegooijen M, Zauber AG, Jemal A. Contribution of screening and survival differences to racial disparities in colorectal cancer rates. Cancer Epidemiol Biomarkers Prev. 2012;21:728-736.

32. Dinh T, Ladabaum U, Alperin P, Caldwell C, Smith R, Levin TR. Health benefits and cost-effectiveness of a hybrid screening strategy for colorectal cancer. Clin Gastroenterol Hepatol. 2013;11: 1158-1166

33. Lansdorp-Vogelaar I, van Ballegooijen M, Zauber AG, Habbema JD, Kuipers EJ. Effect of rising chemotherapy costs on the cost savings of colorectal cancer screening. J Natl Cancer Inst. 2009;101: 1412-1422.

34. Sheffield KM, Han Y, Kuo YF, Riall TS, Goodwin JS. Potentially inappropriate screening colonoscopy in Medicare patients: variation by physician and geographic region. JAMA Intern Med. 2013;173: 542-550.

35. Subramanian S, Tangka FK, Hoover S, et al. Costs of planning and implementing the CDC's Colorectal Cancer Screening Demonstration Program. Cancer. 2013;119(suppl 15):2855-2862.

36. Gupta S, Sussman DA, Doubeni CA, et al. Challenges and possible solutions to colorectal cancer screening for the underserved. J Natl Cancer Inst. 2014;106:dju032.

37. Wender R. Reaching $80 \%$ by 2018: What It's Really Going To Take [Powerpoint presentation]. Presented at The Ninth Annual New York Citywide Colon Cancer Control Coalition (C5) Summit; June 4, 2014; New York, NY. Available at: http://c5nyc.org/2014-c5-summitpresentations/\#sthash.2hJy6pdA.dpuf. Accessed January 1, 2015. 